\title{
The application of anticoagulant therapy to sepsis
}

\author{
Jecko Thachil ${ }^{1}$ and Toshiaki lba ${ }^{2^{*}}$
}

\begin{abstract}
Since the withdrawal of recombinant-activated protein C, the anticoagulant therapy for sepsis was taken no notice. For instance, the international sepsis guidelines did not share a space for this therapy. However, we can see the signs of change recently. The Surviving Sepsis Campaign Guidelines 2016 introduced the development of recombinant thrombomodulin, and the European Society of Intensive Care Medicine released comments on this subject. However, since small but important discrepancy was recognized between the standpoints of Japan (more aggressive) and other countries (rather conservative), we intend to discuss on this point.
\end{abstract}

Keywords: Sepsis, Anticoagulants, Disseminated intravascular coagulation

\section{Main text}

Recently, the Intensive Care Medicine published a pro and con debate entitled 'Should all patients with sepsis receive anticoagulation?' [1, 2]. We read the above articles with surprise since the anticoagulant therapies had been almost ignored in the countries other than Japan. Though these editorials were concise, they contain many important messages. Thus, we would like to introduce the essence of those articles and try to make some comments on them.

Septic coagulopathy represented by disseminated intravascular coagulation (DIC) is Janus-faced. It is a part of the frontliners of the host defence against infection but induces organ dysfunction at the same time [3]. Meziani et al. [1] mentioned that the coagulation disorder is an almost universal event in sepsis, and thus, anticoagulation may have favourable effects from the standpoint of pros; however, we think we have to remind that not all patients can get benefits from the anticoagulant therapy. Numbers of randomized controlled trials (RCT) failed to show the benefit of multiple agents. From the standpoint of cons, van der Poll et al. [2] asserted that the universal administration of anticoagulants cannot be recommenced because of the increased risk of bleeding and the possibility of hampering coagulation-assisted clearance of pathogens. Well, we agree on both opinions and suppose that the selection of the right

\footnotetext{
* Correspondence: toshiiba@juntendo.ac.jp

${ }^{2}$ Department of Emergency and Disaster Medicine, Graduate School of Medicine, Juntendo University, 2-1-1 Hongo Bunkyo-ku, Tokyo 113-8421, Japan

Full list of author information is available at the end of the article
}

target is the fundamental condition for the success in the treatment. Indeed, the recent studies repeatedly reported the beneficial effect was seen only in the patients with severe coagulation disorder [4]. In addition, the subgroup analyses in the KyberSept and PROWESS trials revealed the trend towards greater risk reduction in mortality in the patients with DIC than in the patients without $[5,6]$. Therefore, we think the stratification to identify the most suitable patient population is essential for the success in the anticoagulant therapies. More detailed analysis is required to find the adequate timing, dose, and duration for each anticoagulant. For that purpose, we insist the need for more active investigation; performing not only the RCTs but also the other styles of clinical studies should be carried out. Regarding the international difference, we realized the prevalence of anticoagulation is more dominant in Japan since the diagnosis of DIC has been a part of the standard care for sepsis management, whereas the other countries are more conservative because the measurements of the coagulation markers are not the routine work. This difference should influence the result of the anticoagulant therapy.

The current obstacle is the lack of the appropriate diagnostic tool. There are several popular diagnostic criteria for DIC, but none of them were specially designed for sepsisassociated DIC. Sepsis-induced coagulopathy (SIC) is uniquely characterized by coagulation activation with oversuppression of fibrinolysis and a high incidence of organ dysfunction [7]. Thus, we need to establish proper diagnostic criteria for SIC by using the data from homogenous 
group of patients with the same basic pathophysiology and clinical characteristics. For example, we have ever introduced the diagnostic criteria that include the baseline antithrombin activity for the application of antithrombin substitution [8]. With regard to the use of thrombomodulin, a large-scale randomized controlled trial (RCT) is in progress, a phase III study for recombinant human soluble thrombomodulin [9]. This RCT targets on the subset of sepsis patients with organ dysfunction and prothrombin time INR of more than 1.4. However, whether this category is adequate has not been validated yet. For the adequate target of recombinant thrombomodulin, Yamakawa et al. [10] revealed a significant correlation between effect size and baseline severity, and Yoshimura et al. [11] reported that the effect was most remarkable when the baseline APACHE II score was between 24 and 29. Eventually, we propose to include the indicator of organ dysfunction for the future design of SIC. Though we still do not know what are the ideal indicators, serum lactate level, damage-associated molecular markers, thrombelastography, thrombin generation test, and clot waveform analysis are the possible candidates. In the recent editorial in Intensive Care Medicine, Levi M. et al. introduced the usefulness of measuring microparticles, and clot strength and elasticity as another options [12].

In contrast to the international 'Surviving Sepsis Campaign Guidelines 2016 (SSCG)', the latest 'Japanese Clinical Practice Guidelines for Management of Sepsis and Septic Shock (J-SSCG) [13]' recommend the supplementation of antithrombin for sepsis patients with DIC. The background of the discrepancy is explained as follows: though the largest RCT named KyberSept failed to show the survival benefit in the group treated with antithrombin, the subgroup analysis found the positive signal from the treatment [5]. SSCG adopted the result of KyberSept, and J-SSCG adopted it from the subgroup analysis. In contrast to the positive evaluation for antithrombin, the recommendation for recombinant thrombomodulin was postponed in both guidelines since the sufficient data has not been obtained yet.

During the course of setting the guidelines, the cost of anticoagulation was the subject of discussion. The anticoagulant therapy with antithrombin for 3 days costs approximately US $\$ 2000$, and 6 days treatment with recombinant thrombomodulin costs almost US $\$ 4000$. These medical expenses are the common prices when patients are administered antithrombin or thrombomodulin for DIC treatment in Japan, and the cost-effectiveness is an unsolved issue of these therapies. For more convincing evaluation, advanced analyses such as the comparisons of ICU-free days, hospitalization-free days, and total cost should be performed. In addition, the risk of bleeding is the other issue. It may be permissive [14], but still not ignorable especially in the patients who underwent surgical interventions. The risk of bleeding was reported to be high, when the high dose of antithrombin was applied. Indeed, in the KyberSept trial, total of 30,000 IU (loading dose of 6000 IU, followed by a continuous infusion of $6000 \mathrm{IU} /$ day for 4 days) was administered and the bleeding incidence was over $20 \%$ [15]. In contrast, the incidence was around 5\% when the supplemental dose (1500 IU/day for 3 days) was normally administered for the treatment of DIC in Japan. As for recombinant thrombomodulin, Eguchi et al. [16] reported that serious bleeding was recognized in 121 cases out of 1787 sepsis-induced DIC patients treated with recombinant thrombomodulin $(6.8 \%)$ in their post-marketing survey. In contrast, the phase $2 \mathrm{~b}$ study performed outside Japan reported the serious bleeding was recognized in 19 out of 370 patients $(5.1 \%)$ [17].

In summary, the observation that not one but various anticoagulants are effective suggests the effectiveness of anticoagulant therapy, and the result that the efficacy was recognized only in the patients with severe coagulation disorder further supports this idea. Though high cost and risk of bleeding are possible disadvantages, we think the anticoagulation may be one of the most promising treatments for septic coagulopathy.

\section{Abbreviations \\ DIC: Disseminated intravascular coagulation; RCT: Randomized controlled trial; SIC: Sepsis-induced coagulopathy \\ Acknowledgements \\ None. \\ Funding \\ None. \\ Availability of data and materials Not applicable. \\ Authors' contributions \\ JT and TI had the concept. TI wrote the draft, and JT helped in the editing. All authors read and approved the final manuscript.}

Authors' information

Jecko Thachil is the chairperson of the International Society of Thrombosis and Haemostasis/DIC Scientific and Standardization Committee. Toshiaki Iba is the co-chair of the International Society of Thrombosis and Haemostasis/ DIC Scientific and Standardization Committee.

\section{Competing interests \\ JT has no competing interests to declare. TI receives research fund from Nihon Parma.}

\section{Consent for publication}

Not applicable.

Ethics approval and consent to participate Not applicable.

\section{Publisher's Note}

Springer Nature remains neutral with regard to jurisdictional claims in published maps and institutional affiliations. 


\section{Author details}

'Department of Haematology, Manchester Royal Infirmary, Manchester, UK. ${ }^{2}$ Department of Emergency and Disaster Medicine, Graduate School of Medicine, Juntendo University, 2-1-1 Hongo Bunkyo-ku, Tokyo 113-8421, Japan

Received: 5 April 2017 Accepted: 24 May 2017

Published online: 30 May 2017

\section{References}

1. Meziani F, Gando S, Vincent JL. Should all patients with sepsis receive anticoagulation? Yes. Intensive Care Med. 2017:43:452-4.

2. van der Poll T, Opal SM. Should all septic patients be given systemic anticoagulation? No. Intensive Care Med. 2017:43:455-7.

3. Engelmann B, Massberg S. Thrombosis as an intravascular effector of innate immunity. Nat Rev Immunol. 2013;13:34-45.

4. Umemura $Y$, Yamakawa $K$, Ogura $H$, Yuhara $H$, Fujimi S. Efficacy and safety of anticoagulant therapy in three specific populations with sepsis: a metaanalysis of randomized controlled trials. J Thromb Haemost. 2016;14:518-30.

5. Kienast J, Juers M, Wiedermann CJ, Hoffmann JN, Ostermann H, Strauss $R$, et al. Treatment effects of high-dose antithrombin without concomitant heparin in patients with severe sepsis with or without disseminated intravascular coagulation. J Thromb Haemost. 2006;4:90-7.

6. Dhainaut JF, Yan SB, Joyce DE, Pettilä V, Basson B, Brandt JT, et al. Treatment effects of drotrecogin alfa (activated) in patients with severe sepsis with or without overt disseminated intravascular coagulation. J Thromb Haemost. 2004;2:1924-33

7. Semeraro N, Ammollo CT, Semeraro F, Colucci M. Sepsis, thrombosis and organ dysfunction. Thromb Res. 2012;129:290-5.

8. Iba T, Di Nisio M, Thachil J, Wada H, Asakura H, Sato K, et al. Revision of the Japanese Association for Acute Medicine (JAAM) disseminated intravascular coagulation (DIC) diagnostic criteria using antithrombin activity. Crit Care. 2016;20:287.

9. https://clinicaltrials.gov/ct2/show/NCT01598831?term=ART-123\&rank=4

10. Yamakawa K, Aihara M, Ogura H, Yuhara H, Hamasaki T, Shimazu T. Recombinant human soluble thrombomodulin in severe sepsis: a systematic review and meta-analysis. J Thromb Haemost. 2015;13:508-19.

11. Yoshimura J, Yamakawa K, Ogura H, Umemura Y, Takahashi H, Morikawa M, et al. Benefit profile of recombinant human soluble thrombomodulin in sepsis-induced disseminated intravascular coagulation: a multicenter propensity score analysis. Crit Care. 2015;19:78.

12. Levi M, Schultz MJ. What do sepsis-induced coagulation test result abnormalities mean to intensivists? Intensive Care Med. 2017:43:581-3.

13. http://www.jaam.jp/html/info/2016/pdf/J-SSCG2016_ver2.pdf\#search= \%27Japanese+Clinical+Practice+Guidelines+for+Management+of+Sepsis tand+Septic+Shock\%27

14. Iba T, Gando S, Saitoh D, Wada H, Di Nisio M, Thachil J. Antithrombin supplementation and risk of bleeding in patients with sepsis-associated disseminated intravascular coagulation. Thromb Res. 2016;145:46-50.

15. Warren BL, Eid A, Singer P, Pillay SS, Carl P, Novak I, et al. Caring for the critically ill patient. High-dose antithrombin III in severe sepsis: a randomized controlled trial. JAMA. 2001;286:1869-78.

16. Eguchi Y, Gando S, Ishikura H, Saitoh D, Mimuro J, Takahashi H, et al. Postmarketing surveillance data of thrombomodulin alfa: sub-analysis in patients with sepsis-induced disseminated intravascular coagulation. J Intensive Care. 2014;2:30.

17. Vincent JL, Ramesh MK, Ernest D, LaRosa SP, Pachl J, Aikawa N, et al. A randomized, double-blind, placebo-controlled, phase $2 \mathrm{~b}$ study to evaluate the safety and efficacy of recombinant human soluble thrombomodulin, ART-123, in patients with sepsis and suspected disseminated intravascular coagulation. Crit Care Med. 2013;41:2069-79.

\section{Submit your next manuscript to BioMed Central and we will help you at every step:}

- We accept pre-submission inquiries

- Our selector tool helps you to find the most relevant journal

- We provide round the clock customer support

- Convenient online submission

- Thorough peer review

- Inclusion in PubMed and all major indexing services

- Maximum visibility for your research

Submit your manuscript at www.biomedcentral.com/submit
Biomed Central 